\title{
The Comparison of Offline Class Learning Outcomes by Applying Online Class Learning Models for Practice Subject to the Dancing Art Students, Faculty of Art and Design Education, Indonesia University of Education
}

\author{
Yuliawan Kasmahidayat*, Agus Budiman, Ria Sabaria \\ Department of Dancing Art Education, Faculty of Art and Design Education/ Magister of Art Education \\ Universitas Pendidikan Indonesia \\ Bandung, Indonesia \\ *kasmahidayat@upi.edu, topjete@yahoo.com, sabaria@upi.edu
}

\begin{abstract}
This research was aimed to find out the comparison of result in learning between offline class and online class or called as online learning model (OLM). By optimizing the improvement of knowledge and information technology, the students were given a chance to optimize their skill in online class. The researchers used aesthetic multimedia technology to make the students' interest in learning the material. Developing OLM used online interactive learning model technique by taking advantage of social media and cellphone as tools. The subject of this research was students of undergraduate of dancing art education program, faculty of art and design education. This research used mixed methods theory. The comparison of students' understanding through dancing art practical subject by using OIL technique and result of learning through offline class was the main analysis of the result in this research. The data was collected by using questionnaire, result of the practical subject test and online class as the design research map that applied in two different classes. The first class showed that learning by offline class was more success than online class (OLM). In other hand, the second class showed the opposite. The result of this comparison of learning method between offline class and online class and some factors that influenced to this result were being the background to improve the efficiency of learning on practical subject to the students of dancing art education program, faculty of art and design education, UPI.
\end{abstract}

Keywords-learning system, offline class, online learning model.

\section{INTRODUCTION}

Background of this research inspired by teaching learning process that conducted from home during pandemic Covid-19 that stop people' daily activity. Researcher started online class learning since March 16, 2020, based on the government's appeal and Rector' Decree Number: 0017 of 2020 on Covid 19, it explained that campus activities will be stopped until the end of May 2020 and will be reviewed if there are changes in circumstances. This is the background of online learning that is applied throughout in all study programs at the Indonesia University of Education. In its implementation, it is adjusted to the characteristics of the course.

Offline learning has been implemented since long time ago and it became a conventional form of learning routine, nowadays. For example, introducing themselves, checking attendance, making small talk or joking to make students interested, and so on. Of course it will be difficult if it is done by online class, but in the process, various ways are found so that the learning atmosphere takes place as the process is applied to direct learning.

Online learning certainly not be easy to be implemented because there is no "emotion" or learning experience, there is a distance between students and lecturers. The main focus or goal of learning becomes a learning problem. If the focus of the lesson is on observing flora and fauna in the forest, do students have to go to the forest? Maybe if it wasn't art students it would be a problem. However, art students will certainly bring the space closer to the realm of students' imagination and intuition. Going to the forest means creating an image space for students to represent the forest through their imagination and intuition.

Online learning strategies should be aware of, while learning activities was started. These are aspects that will be a comparison between online class and offline class, revealing both weaknesses and strengths in it. The learning subject that analyzed on this case study was Sumatran Dance practice among 32 students of the Department of Dance and Dance 2018A, and $192018 \mathrm{C}$ students. 
This research used mixed methods; (1) Online learning is not only about the internet, but also secure. Through Learning Management Systems (LMS) in terms of reducing the risk of covid-19, or other problem such as "bullying" in the learning process or in order to develop imaginary and intuition and also provide comfort/security to students in expressing their ideas; (2) Online learning expands access to information and communication in learning. It means, between one student and another student has more access to information and communication than offline class. Discussing in the classroom or while offline class, students tended to be less concerned with each other. Students' understanding on offline class focused on the lecturer, in other hand the students' intellectual development becomes weak; (3) Finding the rhythm of learning is one of the main obstacles of online learning. When students are familiar with the scheduled and during online class, did the students arrange their schedule optimally? when did he study in earnest? Motivate yourself to find your priorities in online class.

\section{Formulation OF PROBLEM}

Based on the exposure in the introduction above, the researchers formulated the problems in this study as follows:

A. How did the learning process through offline class and offline class?

B. How was the comparison of the result of learning process through offline class and offline class?

\section{AIMS OF THE RESEARCH}

Aims of this research were to find out and describe:

A. Find out the learning process through offline class and offline class.

B. Find out the comparison of the result of learning process through offline class and offline class.

\section{LITERATURE REVIEW}

\section{A. Offline Class Theory}

Offline class became one of leaning model that can be used in the teaching and learning process at various levels, starting from the Kindergarten, Primary, Junior High School, High School, and College. Offline class is determined based on the type of learning process that is applied in the learning process. Learning is a process of changing students' behavior. Build up their knowledge, not knowing to knowing, not being able to, being unable to being able, not understand to understand and so on [1].

The type of learning process is determined based on the initial preparation made by a teacher before carrying out the teaching and learning process in front of their students. The type of learning process of dance practice courses is considered more effective while performed in the form of class/ offline class. However, in certain conditions where the offline class learning process cannot be applied, the teacher must be able to determine other types of learning process that effective to reach the goals of the learning activity, for example online class learning.

Offline class learning is a very common learning all this time. This type of learning must be planned specifically based on various principles of developing teaching materials and standard of process in its implementation. On this offline class, teaching skills of the teacher determines whether the teaching learning process will be successful or not. Abilities that must be mastered by a teacher, for example, mastery of the concept of subject matter and the environment in which learning takes place.

The concept of learning materials and learning environment can be developed appropriately according to the conditions of the learners through various learning models that have been widely developed today. According to Santyasa [2] a learning model that can be applied to a study should be coherent with the nature of education in the field of study. However, philosophically the purpose of learning is to facilitate students to become critical, humanist, flexible, and adaptive thinkers in applying knowledge in the real world. Learning models that can accommodate these goals are those based on the constructivist paradigm as an alternative paradigm.

\section{B. Online Class Theory}

Online Communication or which stands for communication in a network is a way of communication that conveys and receives messages through the internet. Communication that occurs in all worlds can be called communication in cyberspace or cyberspace. (Online Knowledge Media Portal) Regarding Knowledge [3].

\section{Function of Online Communication}

Warschauer further, M. 2001 PP.207-212 [4], suggests the definition of online communication leads to reading, writing and communicating by using computer networks. There are several functions of online communication as the follows:

- Information, online communication that has a function to be a media for sending messages and information to the information recipients,

- Control, Controlling and managing information as an individual or group authority;

- Motivation, Online communication can also refer to the work and enthusiasm of employees towards their work; Emotional Expression, Online communication can be representative of individuals or groups;

- Time Saver, efficient communication is carried out,

- Cost Saver, lower internet quota prices, which is very helpful once online communication is running; 
- Performed anywhere, it means whether in the morning, afternoon, evening, and night there is no problem when communicating online;

- Technology, online communication starts from the science of education which at that time was used as research material;

- Communication intensity, ease of communication makes communication intensity increase without any restrictions:

- Participation, online communication made participation in the sense of adding individuals or groups to the communication process increasing;

- Control, communication process can also be supervised by the Minister of Communications as a domestic communications control;

- Encouragement, e.g. a writer who is encouraged to write useful writing due to the easy access to communication;

- Ideas Maker, writing on internet networks can be a source of ideas for individuals who read them;

- Media Social, e.g. Facebook, which is a social communication media that can assist in social activities;

- The function of the state, online communication to assist the government in delivering information to the public.

\section{Aims of Online Communication}

The aims of the online communication were to optimized the advancement of science and information communication technology; students were given the freedom to optimize their abilities in learning online.

The objectives of online communication are as follows; (a) Sharing resources; (b) Communication media; (c) Data integration; (d) Data security; (e) Time efficiency; (f) Cost efficiency; (g) Development and maintenance; (h) As a control; (i) Easy to manage; (j) Can be controlled remotely; (k) Increased communication intensity; (l) Increased communication participation; (m) Provide information; (n) Web browsing.

\section{E. Research Method}

Online learning is the maximum utilization of internet networks related to advancement of information and communication as facilities for students' learning. The online learning approach has different characteristics to offline class learning. Online Learning is a one-way communication between lecturers and students, conducted from their own homes through online media. While offline class learning is a direct learning that performed in a classroom or dance practice room
In this research, researcher made the online class learning to build and create knowledge independently of students. Researcher was also collaborated between teachers and learners, either offline class learning and online class learning in order to get the comparison of knowledge and learning outcomes that will raise problems as well as solve problems together (social constructivism), in both of that learning method.

Researchers will examine forms of inclusive learning communities as a result of online learning. Researchers will prioritize; media pages (websites) that can be accessed via the internet, computer-based learning, virtual classes, and / or digital classes as a center for comparative studies with offline class learning. The flexibility of learning time in student online learning becomes a clear, specific, observable, and measurable comparison of learning objectives in changing learner behavior.

In this case study, Sumatra Dance practice courses in the Department of Dance Arts Education Class of 2018A, there are 30 students. The questions on the questionnaire about lectures online are illustrated in the figure 1 below:

\section{Questionnaire A: Learning through Offline Class Method}

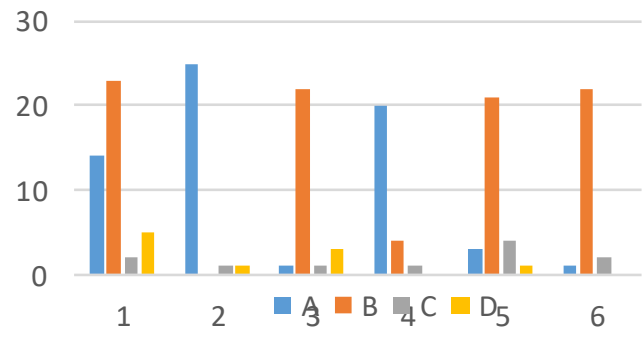

Fig. 1. Questionnaire A: Learning through offline class method.

The figure 1 above is the answer to 6 (six) questions in the questionnaire about offline class:

- The information provided in offline class has the function to: (a) Facilitate the learning process; (b) Facilitate the observation of practical materials; (c) One-way information; (d) Proper communication media.

- Control and arrangement of information in offline class creates communication and authority between: (a) Lecturers and Students; (b) Small groups; (c) medium groups; (d) Assistant Lecturer.

- Online learning communication may also refer to the work and spirit between: (a) the Seller and the buyer; (b) Lecturers and students; (c) Leaders and employees; (d) Lecturers and assistants. 
- Emotional Expressions in offline class can be a communication between individual or group representatives and the teaching lecturer: (a) Yes; (b) Doubt; (c) No; (d) Unclear.

- Time for communication at offline class were: (a) Flexible as students wish; (b) Efficiently performed; (c) Very limited; (d) Whenever.

- Cost savers, not using excessive internet quotas, cheap is very helpful on offline class communication: (a) Disagree; (b) Doubt; (c) Agree; (d) Unclear.

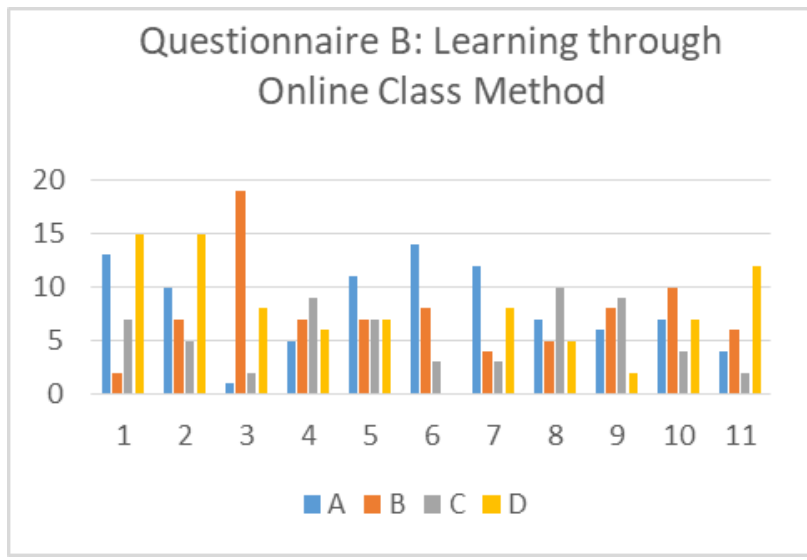

Fig. 2. Questionnaire B: Learning through online class method.

The figure 2 above is the answer to 11 (eleven) questions in the questionnaire about online class method:

- The information provided in online lectures has the following functions: (a) The media for delivering messages; (b) clarifying the material; (c) Information to the recipient of the information; (d) Communication media.

- Control and arrangement of information in online lectures creates communication and authority between; (a) individual; (b) small groups; (c) medium groups; (d) lecturers.

- Communication while learning activity by online class can also refer to the work and spirit between: (a) the Seller and the buyer; (b) Lecturers and students; (c) Leadership and work; (d) Lecturers and assistants.

- Emotional Expression in Online learning can be a communication between an individual or group representative and lecturer;: (a) Yes; (b) Doubt; (c) No; (d) Unclear.

- Time for communication at offline class were; (a) Flexible as per the individual's wishes; (b) Efficiently performed; (c) Very limited; (d) At will.
- Cost saver, with lower internet quota prices is very helpful on Online communication is running; (a) Disagree; (b) Doubt; (c) Agree; (d) It is not clear.

- Online lectures can be done anywhere, as well as at any time you want; (a) Agree; (b) Strongly disagree; (c) Disagree; (d) Doubt.

- Technology, Online communication began when the science of education used as research material: (a) False; (b) Doubt; (c) True; (d) Don't know.

- The intensity of communication in online lectures, provides ease of communication and increases the intensity of communication without any limitations: (a) True; (b) Has limitations; (c) Wrong; (d) Very easy.

- Communication through online increases participation of; (a) Adding an individual or group to its learning process;(b) Adding an individual or group to its communication process; (c) Restrict communication in its learning process; (d) Limit the participation of individuals and groups in their communications.

- The communication process contained in Online lectures has limitations, because it is controlled and supervised by the Minister of Communication as the domestic communications supervisory agency: (a) Not so; (b) Occasionally; (c) True; (d) Don't know.

The analysis on the questionnaire in the study entitled: The Comparison of Offline Class Learning Outcomes by Applying Online Class Learning Models for Practice Subject to the Dancing Art Students, Faculty of Art and Design Education, Indonesia University of Education, became the fundament that aims to compare the results of offline class learning with online learning model or Online Learning Model (OLM). Comparison of students' answers to dance practice with OIL techniques and learning outcomes through offline class learning techniques, is the main analysis produced in this study.

The data collected, both through questionnaires, dance practice results tests, online class, became a map of research designs that are applied in two different classes. It was illustrating; In the first class, offline class learning outcomes were more successful than online (OLM), while the second class achieved the opposite. The results of the comparison of lectures and the various factors that cause differences in achievement, were used as the basis for increasing the efficiency of learning practical subjects for dancing art education students at FPSD UPI.

\section{F. Data Processing Guidelines}

This research used mixed methods. Online learning is not just an aspect of the internet, it is the security aspect (secure). Through Learning Management Systems (LMS) in terms of reducing the risk of covid-19 or other problem such as "bullying" in the learning process or in order to develop 
imaginary and intuition and also provide comfort/secure to students in expressing their ideas.

Online learning expands access to information and communication in learning. It means that between one student and another student has more access to information and communication if necessary than during limited while offline class discussions. Discussing while offline class learning, students tended to be less concerned with each other. Understanding concepts of offline class learning was only focusing on lecturer, students' intellectual development becomes weak.

Finding the rhythm of learning is one of the main obstacles of online learning. When students are familiar with the scheduled of their class and during online class lecture, students have to set their own optimal schedule and seriously and motivate yourself to find virtues in online lectures.

Processing the results of activities using descriptive analytical exposure, both quantitative analysis and qualitative analysis. The processing of the results of activities was guided by the acquisition of documentation and in-depth interviews with related person to this research, entitled: The Comparison of Offline Class Learning Outcomes by Applying Online Class Learning Models for Practice Subject to the Dancing Art Students, Faculty of Art and Design Education, Indonesia University of Education. The data analysis tool used SWOT analysis at the Research Location at the Department of Dancing Art Education, FPSD UPI.

Data collection methods are needed in this activity in the form of primary data and secondary data. Data analysis technique and data processing according to needs, both descriptive, analytical and quantitative and research achievement. The data analysis model used an interactive analysis with 4 components, namely data reduction, data presentation, data collection and research verification. The analysis tool used SWOT analysis.

Swot analysis includes 4 analysis spaces, namely:

- Strength, include: (a) technology has become the living environment in students' daily life; (b) Students are quickly familiar with the various forms of "information" offered through technology; (c) Information technology provides limitless visual engineering possibilities.

- Weaknesses, including: (a) the ability of dance teachers to apply IT in the learning process is inadequate; (b) the arts and culture curriculum in public universities does not include IT applications as one of its basic competencies; (c) tools/computer in universities are generally not compatible with dance learning applications.

- Opportunities, including: (a) IT presents almost unlimited visual engineering possibilities using a variety of computer programs (software); (b) Integrated learning of art learning with ICT and other learning areas (curriculum 2004); (c) The inclusion of communication and information technology in the general school curriculum (curriculum 2004); (d) The use of IT as a media for art work (developments in the world of dancing art).

- Treatment, including: (a) Resistance to the use of computers in the learning of dance art at home; (b) The concept of art disciplines embraced by most teachers as the foundation of art learning in PT; (c) The computer specs for art learning are quite expensive; (d) IT programs specific to Art learning are unavailable; (e) Use of English on almost all computer programs.

The results of the SWOT analysis through the internal and external matrices, obtained results for internal and got a score of 2.34 (medium) and external score of 3.00 (intermediate) while the results of SWOT calculations using the matrices analysis, obtained the following results:

$$
\begin{aligned}
& \text { Strength }(\mathrm{KK})=2 \\
& \text { Weakness }(\mathrm{KL})=-2.4 \\
& \text { Probability }(\mathrm{PL})=3.5 \\
& \text { Threat }(\mathrm{AN})=-1 \\
& \text { So that: } \\
& \text { KK }+ \text { AN }=2+(-1)=1 \\
& \text { KL }-\mathrm{PL}=-2,4+3,5=1,1
\end{aligned}
$$

Based on the results of this analysis, the research strategy is "The Comparison of Offline Class Learning Outcomes by Applying Online Class Learning Models for Practice Subject to the Dancing Art Students, Faculty of Art and Design Education, Indonesia University of Education." This research applied, such as: (1) Reflection on learning; (2) Online Learning Model; (3) Increasing human resource development; (3) Characteristics of dance practice courses; (4) comparative theory; and (5) Characteristics Theory of Online Learning Media.

\section{CONCLUSION}

Advances in communication science and information technology today, allowing for changes in the application of learning models. It has been done Comparing the Results Offline Learning with the Application of Online Learning Models of Practical Courses in Students. Through optimizing the advancement of science and communication information technology, so that students are more free to develop their skills in terms of learning, both offline class and online class.

The data has been collected through questionnaires and tests of dance practice and online learning. The results illustrate; learning achievements, topics, activities, learning strategies, offline learning and online learning are aligned according to research objectives. Comparison of student absorption to dance practice online is the main analysis and the results of lecture comparison can be the basis for improving the efficiency of practical course learning in dance arts education students at FPSD UPI. 


\section{REFERENCES}

[1] I. Hitipiew, Belajar dan Pembelajaran. Malang: Perpustakaan Digital UNM, 2009.

[2] I.W. Santyasa, Model Pembelajaran Inovatif dalam Implementasi. Kurikulum Berbasis Kompetensi. Bali: FPMIPA IKIP Negeri Singaraja, 2005 .
[3] (Portal Media Pengetahuan Online) Seputar Pengetahuan.

[4] H. Shetzer and M. Warschauer, "English throught Web page creation". In J. Murphy \& P. Byrd (Eds), "Understanding the course we teach: Local perspective on English Language teaching". Ann Arbor: University of Michigan Press. 2001. 